\title{
Effect of tryptophan administration on 5HIAA in cerebrospinal fluid in man
}

\author{
D. ECCLESTON, G. W. ASHCROFT, AND T. B. B. CRAWFORD \\ From the M.R.C. Brain Metabolism Unit, Department of Pharmacology, University of Edinburgh
}

J. B. STANTON, D. WOOD, AND P. H. MCTURK ${ }^{1}$

From the Department of Neurology, Northern General Hospital, and Royal Edinburgh Hospital, Edinburgh

Because of the relative inaccessibility of the brain, attempts to quantify in man the rate of cerebral metabolism of any particular compound are fraught with difficulties. Measurements of urinary end products of brain metabolism are often invalidated by the presence of the same metabolites which originate in other tissues. Cerebral arteriovenous differences in the concentration of metabolites may be technically difficult to estimate and rely on the demonstration of a concentration gradient across the brain to evaluate the rate of production. The concentration of metabolites in the cerebrospinal fluid (CSF) may, however, provide an index of the turnover of substances in the brain.

5-Hydroxytryptamine (5HT) is found in high concentration in central structures of brain of animals and man (Garattini and Valzelli, 1965). It appears to be localized in fine neurones whose cell bodies arise in the mid-brain raphe nuclei and ramify both upwards to other structures, including the cortex, and downwards to the spinal cord(Andén, Dahlström, Fuxe, Larsson, Olson, and Ungerstedt, 1966). The function of these 5-hydroxytryptaminergic neurones is not known, but the system has been implicated in the control of sleep (Koella and Czicman, 1966; Oswald, Ashcroft, Berger, Eccleston, Evans, and Thacore, 1966), temperature (Feldberg and Myers, 1964), and central autonomic processes (Brodie and Shore, 1957). Consequently, any technique which determines the turnover rate of 5HT in brain may shed some light on its role in the regulation of these functions.

The metabolite of 5HT, 5-hydroxyindol-3ylacetic (5HIAA), is found both in the train and in CSF. The administration of tryptophan to animals increases the concentration of both 5HT and 5HIAA in brain (Ashcroft, Eccleston, and Crawford, 1965) and of 5HIAA in CSF. The change in the con-

${ }^{1}$ Present address: Royal Edinburgh Hospital. centration of 5HIAA in cisternal CSF in the dog shows a very precise time relation to the changes in brain after an intravenous dose of amino acid, and it seems that the 5HIAA in CSF may be used to make an indirect determination of the concentration in brain (Eccleston, Ashcroft, Moir, ParkerRhodes, Lutz, and O'Mahoney, 1968). In this study, tryptophan was given in man in order to determine the resultant changes in the concentration of 5HIAA in lumbar CSF and to relate this to blood and CSF tryptophan levels.

\section{METHODS}

LUMBAR PUNCTURE Patients who were investigated for neurological disease by lumbar puncture, but had neither gross brain damage nor psychiatric symptoms, were given an oral dose of L-tryptophan $(50 \mathrm{mg} / \mathrm{kg})$ in milk at various times up to 18 hours before sampling CSF. To obviate variable mixing of the CSF patients were rested in bed before lumbar puncture. The first $5 \mathrm{ml}$. of CSF withdrawn was used for the estimation of tryptophan and 5HIAA. Blood was taken for estimation of tryptophan at various times before lumbar puncture.

AIR ENCEPHALOGRAMS Patients who were to be investigated for neurological disorders by air encephalography were given L-tryptophan $(50 \mathrm{mg} / \mathrm{kg}$ ) four hours before the procedure. Five millilitres of fluid were withdrawn, air injected, and a further sample of CSF taken. Patients who were not given tryptophan served as controls.

CHEMICAL ESTIMATION 5HIAA in CSF was estimated by a modification of the procedure of Ashcroft and Sharman (1962). Tryptophan was estimated by the method of Hess and Udenfriend (1959), as modified by Guroff and Udenfriend (1962).

\section{RESULTS}

AIR ENCEPHALOGRAPHY PROCEDURE After the injection of air in control subjects there is a significant 
$(P<0.01$, paired $t$ test) rise in the concentration of 5HIAA in the CSF withdrawn from the lumbar space (Table). In the control subjects there is no difference between concentrations of tryptophan in the fluid samples withdrawn before or after air. Four hours after the dose of tryptophan there is a small, but significant $(P<0.05$, paired $t$ test) rise in the concentration of the amino acid in the CSF sample obtained after the injection of air. The administration of tryptophan four hours before the procedure does not alter either the absolute value of 5HIAA or the ratio of the concentration in the fluid after the injection of air to that before.

\section{TABLE}

CONCENTRATION OF 5HIAA AND TRYPTOPHAN IN LUMBAR CSF BEFORE AND AFTER INJECTION OF AIR IN TWO GROUPS OF PATIENTS, ONE OF WHICH HAD RECEIVED ORAL TRYPTOPHAN (50 MG/KG) FOUR HOURS BEFORE THE PROCEDURE

\begin{tabular}{|c|c|c|c|}
\hline $\begin{array}{l}\quad \text { Group } \\
\text { Control } \\
\text { Tryptophan }\end{array}$ & $\begin{array}{c}\text { 5HIAA in CS } \\
\text { Before air injection } \\
15.7 \pm 1.8(3)^{1} \\
18.8 \pm 1.9(3)\end{array}$ & $\begin{array}{l}F(m \mu g / m l .) \\
\text { After air injection } \\
27 \cdot 7 \pm 5 \cdot 2(3) \\
33 \cdot 3 \pm 2 \cdot 0(3)\end{array}$ & $\begin{array}{c}\text { Mean ratio } \\
1.7 \\
1.8\end{array}$ \\
\hline $\begin{array}{l}\text { Control } \\
\text { Tryptophan }\end{array}$ & $\begin{array}{l}\text { Tryptophan in } \\
0.49 \pm 0.04 \text { (3) } \\
1.9 \pm 0.3 \text { (4) }\end{array}$ & $\begin{array}{l}S F(\mu g / m l .) \\
0.45 \pm 0.08 \text { (3) } \\
2.4 \pm 0.4\end{array}$ & $\begin{array}{l}0.9 \\
1 \cdot 2\end{array}$ \\
\hline
\end{tabular}

1 mean \pm SEM (no. of observations).

LUMBAR PUNCTURE After tryptophan administration the concentration of 5HIAA in lumbar CSF takes some four hours to show an initial rise (Fig. 1). The maximum level is reached between six and 12 hours and is normal again at 18 hours. Tryptophan on the other hand, shows a significant rise at two hours (Fig. 2). High levels occur during the six to 12 hour period as with the 5HIAA, both substances then showing similar rates of disappearance to return to control levels at about 18 hours after tryptophan administration. As expected, blood levels of tryptophan show an early rise, concentrations returning to normal at 12 hours.

\section{DISCUSSION}

The acid metabolite of 5HT, 5HIAA, is not normally detectable in plasma. Active transport mechanisms prevent its accumulation in brain from the blood stream (Moir and Eccleston, 1968), and hence the 5HIAA found in CSF probably has its origin in neural tissue. The gradient in the concentration of the 5HIAA which exists from the ventricles to lumbar space (Ashcroft et al., 1966) is maintained by active transport of the 5HIAA out

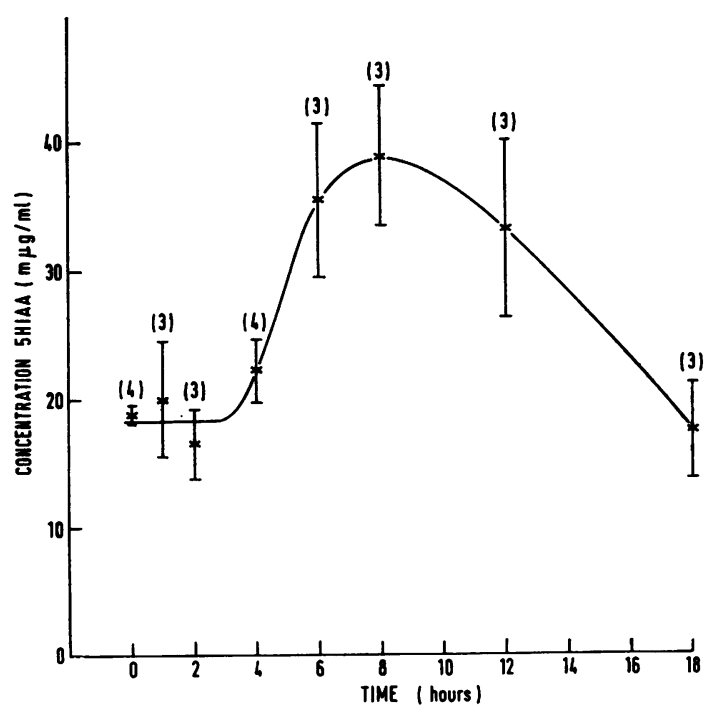

FIG. 1. Concentration (mean \pm S.E.M.) of 5-HIAA $(m \mu g / m l$.$) in lumbar CSF at times up to 18$ hours after $\omega_{\omega}$ oral administration of L-tryptophan $(50 \mathrm{mg} / \mathrm{kg})$. Number i of subjects indicated in parentheses.

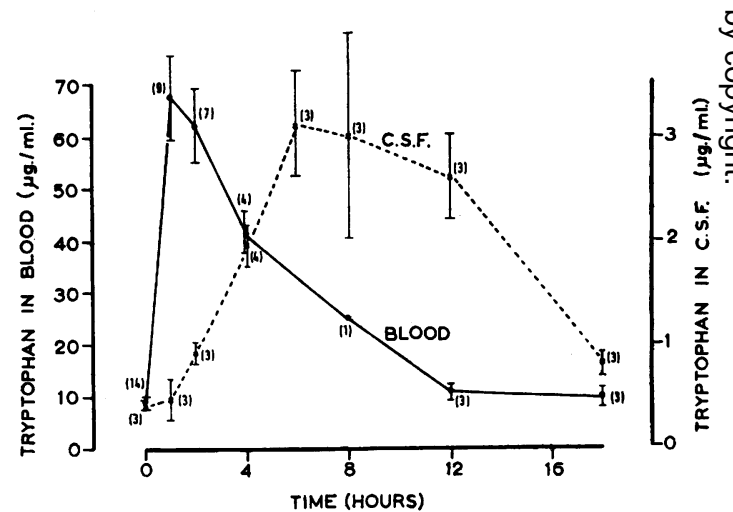

FIG. 2. Concentration (mean \pm S.E.M.) of tryptophin $(\mu \mathrm{g} / \mathrm{ml}$.) in whole blood and CSF at times up to 18 hour.s after oral administration of L-tryptophan $(50 \mathrm{mg} \cdot \mathrm{kg})$. Number of subjects indicated in parentheses.

of CSF by a mechanism resembling renal tubular secretion of organic acids (Pappenheimer, Heisey, and Jordan, 1961; Ashcroft et al., 1968). Entry of air into the subarachnoid space during encephalography leads to mixing and displacement downwards of CSF resulting in a two-fold increase in the concentration of 5HIAA in fluid removed from the lumbar space (Table). The corresponding con- 
centration ratio for tryptophan is unity, indicating a more uniform entry of tryptophan along the CSF space. However, after administration of tryptophan, a small but significant gradient for the amino acid develops, suggesting that the influx under these conditions is not entirely uniform, there being a greater entry at higher levels.

A rise in the concentration of tryptophan in lumbar CSF is already apparent two hours after an oral dose of the amino acid. This is in contrast with the concentration of 5HIAA which only begins to rise some four hours after tryptophan administration and is maximal at about eight hours. This time scale is in good agreement with the work of Pletscher, Bartholini, and Tissot (1967), who found that after intravenous administration, in man, of labelled 3,4-dihydroxyphenylalanine, the precursor of dopamine, there was a slow rise in the concentration of the labelled metabolite, homovanillic acid in lumbar CSF reaching a maximum at eight hours. Entry of 5HIAA into the CSF space does not appear to be uniform, but that in the lumbar region seems to depend on the diffusion of the acid down from higher levels. The delayed increase of this metabolite in lumbar CSF would also suggest that the spinal cord does not contribute to any great extent to the 5HIAA content of lumbar fluid.

The level of 5HIAA in brain and ultimately in CSF is probably a measure of the turnover of 5HT in the 5-hydroxytryptaminergic neurones. It may not, however, give an index of their functional activity. The acid can come from at least two sources. 5HT is released on stimulation of the nerve cell bodies of those neurones situated in the mid-brain raphe nuclei (Aghajanian, Rosecrans, and Sheard, 1967; Eccleston, Padjen, and Randic, 1969) and rapidly converted to 5HIAA. Tryptophan administration also leads to the formation of 5HT and 5HIAA in these neurones. The 5HT formed is not necessarily functionally released and some may merely overspill onto monoamine oxidase and give rise to 5HIAA within the neurone. The total output of 5HIAA from the neurone is ultimately limited by the enzyme tryptophan 5-hydroxylase, which catalyses the formation of 5-hydroxytryptophan, the immediate precursor of 5HT. Nerve stimulation appears to increase the rate of tryptophan hydroxylation probably by stimulation of the tryptophan 5-hydroxylase, thus the administration of tryptophan after stimulation leads to the production of more 5HIAA than in the absence of stimulation (Eccleston, Ritchie, and Roberts, 1970).

In man, then, the lowered concentration of 5HIAA found in the CSF of certain cases of depression (Ashcroft and Sharman, 1960; Dencker, Malm, Roos, and Werdinius, 1966; Ashcroft,
Crawford, Eccleston, Sharman, MacDougal, Stanton, and Binns, 1966) could be the result either of a lowered release of 5HT from 5-hydroxytryptaminergic neurones, or of lowered tryptophan 5-hydroxylase activity setting a lower than normal limit to the synthesis of 5HT. The results of animal experiments (Eccleston, Padjen, and Randic, unpublished observations) suggest that there is a greater production of 5HIAA as a result of tryptophan administration (the amount being limited by the quantity of tryptophan 5-hydroxylase) than by nerve stimulation. Hence a failure of tryptophan administration in patients with depression to produce rises in 5HIAA in CSF comparable with normal subjects (Ashcroft, unpublished observations) would suggest reduced activity of tryptophan 5-hydroxylase in this illness. This could, however, be the late result of reduced functional activity of 5-hydroxytryptaminergic neurones, assuming normal activity has a regulatory role in the formation of this particular enzyme.

\section{SUMMARY}

Oral administration of tryptophan produces a rise in the concentration of the amino acid in lumbar CSF. It also leads to the formation of $5 \mathrm{HT}$ in brain with an increase in the metabolite 5HIAA which appears in lumbar CSF after a delay that is presumably due to the time taken to diffuse down from the brain to the lumbar space.

We wish to thank the nursing staff of the Northern General and Royal Edinburgh Hospitals for their co-operation in this study, and Mrs. I. Ritchie, Mr. R. Dow, and Mr. R. Loose for their technical assistance. Requests for reprints should be addressed to $D$. Eccleston, M.R.C Brain Metabolism Unit, Department of Pharmacology, University of Edinburgh, George Square, Edinburgh EH8 9JZ.

\section{REFERENCES}

Aghajanian, G. K., Rosecrans, J. A., and Sheard, M. H. (1967). Serotonin: Release in the forebrain by stimulation of midbrain raphé. Science, 156, 402-403.

Andén, N. E., Dahlström, A., Fuxe, K., Larsson, K., Olson, L., and Ungerstedt, U. (1966). Ascending monoamine neurons to the telencephalon and diencephalon. Acta. physiol. scand., 67, 313-326.

Ashcroft, G. W., Crawford, T. B. B., Eccleston, D., Sharman, D. F., MacDougal, E. J., Stanton, J. B., and Binns, J. K. (1966). 5-hydroxyindole compounds in the cerebrospinal fluid of patients with psychiatric or neurological diseases. Lancet, 2 , 1049-1052.

Ashcroft, G. W., Dow, R. C., and Moir, A. T. B. (1968). The active transport of 5-hydroxyindol-3-ylacetic acid and 3-methoxy4-hydroxyphenyl acetic acid from a recirculatory perfusion system of the cerebral ventricles of the unanaesthetized dog. J. Physiol. (Lond.), 199, 397-425.

Ashcroft, G. W., Eccleston, D., and Crawford, T. B. B. (1965). 5-hydroxyindole metabolism in rat brain. A study of intermediate metabolism using the technique of tryptophan loading -I Methods. J. Neurochem., 12, 483-492. 
Ashcroft, G. W., and Sharman, D. F. (1960). 5-hydroxyindoles in human cerebrospinal fluids. Nature (Lond.), 186, 1050-1051.

Ashcroft, G. W., and Sharman, D. F. (1962). Drug induced changes in the concentration of 5-OR indolyl compounds in cerebrospinal fluid and caudate nucleus. Brit. J. Pharmacol., 19, 153-160.

Brodie, B. B., and Shore, P. A. (1957). A concept for a role of serotonin and norepinephrine as chemical mediators in the brain. Ann. N.Y. Acad. Sci., 66, 631-642.

Dencker, S. J., Malm, U., Roos, B.-E., and Werdinius, B. (1966). Acid monoamine metabolites of cerebrospinal fluid in mental depression and mania. J. Neurochem., 13, 1545-1548.

Eccleston, D., Ashcroft, G. W., Moir, A. T. B., Parker-Rhodes, A., Lutz, W., and O'Mahoney, D. P. (1968). A comparison of 5 -hydroxyindoles in various regions of dog brain and cerebrospinal fluid. J. Neurochem., 15, 947-957.

Eccleston, D., Padjen, A., and Randic, M. (1969). Release of 5-hydroxytryptamine and 5-hydroxyindol-3-ylacetic acid in the forebrain by stimulation of the mid-brain raphé. J. Physiol. (Lond.), 201, 22-23P.

Eccleston, D., Ritchie, I. M., and Roberts, M. H. T. (1970). The long term effects of midbaain stimulation on 5-hydroxyindole synthesis in rat brain. Nature (Lond.), in press.

Feldberg, W., and Myers, R. D. (1964). Effects on temperature of amines injected into the cerebral ventricles. A new concept of temperature regulation. J. Physiol. (Lond.), 173, 226-237. Garattini, S., and Valzelli, L. (1965). Serotonin, p. 356. Elsevier:을
London.

Guroff, G., and Udenfriend, S. (1962). Studies on aromatic amino acid uptake in brain in vivo. Uptake of phenylalanine and of tryptophan; inhibition and stereoselectivity in the uptake of tyrosine by brain and muscle. J. biol. Chem., 237, 803-806.

Hess, S. M., and Udenfriend, S. (1959). A fluorometric procedure for the measurement of tryptamine in tissues. J. Pharmacol. exp. Ther., 127, 175-177.

Koella, W. P., and Czicman, J. (1966). Mechanism of the EEGsynchronizing action of serotonin. Amer. J. Physiol., 211, 926-934.

Moir, A. T. B., and Eccleston, D. (1968). The effects of precursor loading in the cerebral metabolism of 5-hydroxyindoles. J. Neurochem., 15, 1093-1108.

Oswald, I., Ashcroft, G. W., Berger, R. J., Eccleston, D., Evans, J. I., and Thacore, V. R. (1966). Some experiments in the chemistry of normal sleep. Brit. J. Psychiat., 112, 391-399.

Pappenheimer, J. R., Heisey, S. R., and Jordan, E. F. (1961). Activtransport of diodrast and phenolsulfonphthalein from cerebro- $\overparen{\nabla}$ spinal fluid to blood. Amer. J. Physiol., 200, 1-10.

Pletscher, A., Bartholini, G., and Tissot, R. (1967). Metabolic fate of $L-\left({ }^{14} \mathrm{C}\right)$ DOPA in cerebrospinal fluid and blood plasma of humans. Brain. Res., 4, 106-109. 